\title{
Demographic Profile and Outcome of Mechanically Ventilated Children in a Tertiary Care Hospital of a Developing Country
}

\author{
Sahoo B ${ }^{1}$, Jain $M K^{2}$, Thakur $B^{3}$, Mishra $\mathbf{R}^{4}$, Patnaik $\mathbf{S}^{5}$
}

\section{Abstract}

Introduction: The need for mechanical ventilation (MV) is an absolute indication for admission to Paediatric intensive care unit (PICU). Management of children requiring invasive ventilation in resource limited developing countries is challenging. Scare data is available from Asian countries regarding use of MV in PICUs. The objectives of this study were to determine the clinical profile, characteristics, common causes for ventilation, ventilation related complications and final outcome of these patients. Material and Methods: A retrospective study of children requiring ventilator support in PICU of Kalinga Institute of Medical Sciences from January 2014 to December 2016 was done. Data collected included epidemiological trends, indications for ventilation, complications, length of stay on ventilator and outcome. Results: A total of 1172 patients were admitted to PICU, 101 (8.6\%) patients required MV. $42 \%$ of the mechanically ventilated patients were infants and $75 \%$ were males. Impending respiratory failure (34.6\%) and low Glasgow coma scale (17.8\%) were the commonest indication for ventilation in this study. The median length of MV was 2.1 days. The mortality rate of these children was $38.6 \%$. We report the epidemiological trends, frequency, indications and outcomes of children requiring ventilator support in PICU. Analysis of this data can be helpful in improving outcome in future by planning better treatment strategies. Conclusion: The frequency of MV in our PICU is low. Respiratory failure was the most common reason for mechanical ventilation.

Key words: Mechanical ventilation, Indication, Outcome, PICU, Respiratory failure.

\section{Introduction}

ntroduction of several new and advanced modes of ventilation has led to continuous evolution in mechanical ventilation. Although patients receiving mechanical ventilation represent only a small proportion of hospitalizations, it is a life-saving invasive technology which is expensive, labour-intensive and is associated with various complications. The percentage of children receiving mechanical ventilation in PICUs ranges from $17-64 \%$ in developed countries ${ }^{1,2}$. The mortality rate is higher in children who require $\mathrm{MV}$ as compared to those who do not require respiratory support ${ }^{3}$. Mortality of a ventilated
${ }^{1}$ Dr. Bandya Sahoo, MBBS, MD, Associate Professor, ${ }^{2}$ Mukesh Kumar Jain, Assistant Professor, ${ }^{3} \mathrm{Dr}$. Bhaskar Thakur, Biostastitian, ${ }^{4}$ Dr. Reshmi Mishra, MBBS, MD, Associate Professor, ${ }^{5} \mathrm{Dr}$. Sibabratta Patnaik, MBBS, MD, Assistant Professor. All from the Department of Paediatrics, Kalinga Institute of Medical Sciences, Bhubaneswar, Odisha, India.

\section{Address for correspondence}

Dr. Mukesh Kumar Jain, Assistant professor Department of Paediatrics, Kalinga Institute of Medical Sciences,

Bhubaneswar, Odisha, India-751024.

Tel No; +919437545680

E-mail: mukesh26.jain@gmail.com

\section{Acknowledgements: None \\ Funding: Nil \\ Conflict of Interest: None \\ Permission from IRB: Exempted}

\section{How to cite}

Sahoo B, Jain MK, Thakur B, Mishra R, Patnaik S. Demographic Profile and Outcome of Mechanically Ventilated Children in a Tertiary Care Hospital of a Developing Country. J Nepal Paediatr Soc 2018;38(1):14-18.

doi:http://dx.doi.org/10.3126/jnps.v38i1.18879

This work is licensed under a Creative Commons Attribution 3.0 License. 
patient depends on factors present during the initiation of ventilation, complications which develop during the course of MV and the associated co- morbidities. Hence, inorder to improve the therapeutic strategies intensivists should have the knowledge of epidemiology of patients requiring $\mathrm{MV}$ and the risk factors of mortality which can be helpful to give quality care to ventilated patients ${ }^{4}$. Data available from developing countries (particularly Asian countries) regarding use of $\mathrm{MV}$ in PICU is scarce ${ }^{5,6}$. The objective of this study was to assess the demographic profile, frequency, indications and complications of mechanical ventilation. It also includes the number of ventilated days and immediateoutcome of these children in the PICU of a tertiary-care hospital of a developing country. This can improve the understanding of patients who require $\mathrm{MV}$ which in turn may help to improve therapeutic strategies.

\section{Material and Methods}

This retrospective clinical study was conducted from January 2014 to December 2016, in the PICU of Kalinga Institute of Medical sciences, a tertiary care teaching hospital. Our PICU is 10 bedded and assisted by four full time intensivists, three senior paediatric residents, one nurse for two patients and one nurse for each ventilated patient. The medical records of all children who received mechanical ventilation in a paediatric intensive care unit was reviewed and the data collected in each patient included: the basic demographic profile (age, gender, diagnosis), indications for MV, length of MV and PICU stay, complications of MV and outcome of patient. Patients were monitored clinically as well as using multiparameter cardiac monitor. The decision to intubate was clinical along with various other parameters such as arterial blood gas analysis, Glasgow Coma Scale $<8$, cardiopulmonary arrest, apnoea, refractory shock, postoperative patients and patients with refractory status epilepticus. All the patients from one month to 15 years of age, admitted to the PICU, who required mechanical ventilation were included in the study group.

Data was collected on a proforma and entered into Excel sheet. The data was analysed to find out various indications for mechanical ventilation, complications attributed to mechanical ventilation and associated comorbidities.

Descriptive statistics were used to evaluate baseline characteristics. All the Categorical variables were expressed as frequency and percentage. The continuous variables were expressed as median with range. Since the entire continuous variables were not normally distributed, a Kruskal wallis analysis of variance followed by manual multiple comparison test (ranksum test between any two group) was applied. The qualitative parameter was expressed as number and percentage ( $\mathrm{n}$ and \%) and analysed using Fisher's exact test. A $p$-value of $<0.05$ was considered as statistically significant. The statistical analysis was carried out using the software Stata 13.1.

\section{Results}

A total of 1172 patients were admitted to the PICU during the three years study period, and 101 (8.6\%) of them received invasive mechanical ventilation. Forty two percent of the ventilated patients were infants. Majority of the study population were males (75\%). The most common reasons for initiation of MV were impending respiratory failure (34.6\%) and low Glasgow coma scale (17.8\%). Other causes were shock (13.8\%), status epilepticus (10.9\%) and ALI/ARDS (Acute lung injury/Acute respiratory distress syndrome). The major underlying aetiology for invasive ventilation was bronchopneumonia associated with respiratory failure. Based on indications for mechanical ventilation patients in our study were divided into four major groups: Group A included children with neurological illness (31.6\%), Group B-respiratory illness (40.6\%), Group C-cardiac diseases (19.8\%) and Group D- others (7.9\%). The distribution of the study groups is shown in Fig 1.

Major complications observed in our study were ventilator associated pneumonia in six patients, pneumothorax in three patients, and upper lobe collapse in one patient and spontaneous extubation in one patient. Sixty seven percent of mechanically ventilated children had associated co-morbid conditions. Congenital heart disease and multiorgan dysfunction were the major comorbid conditions in our study.

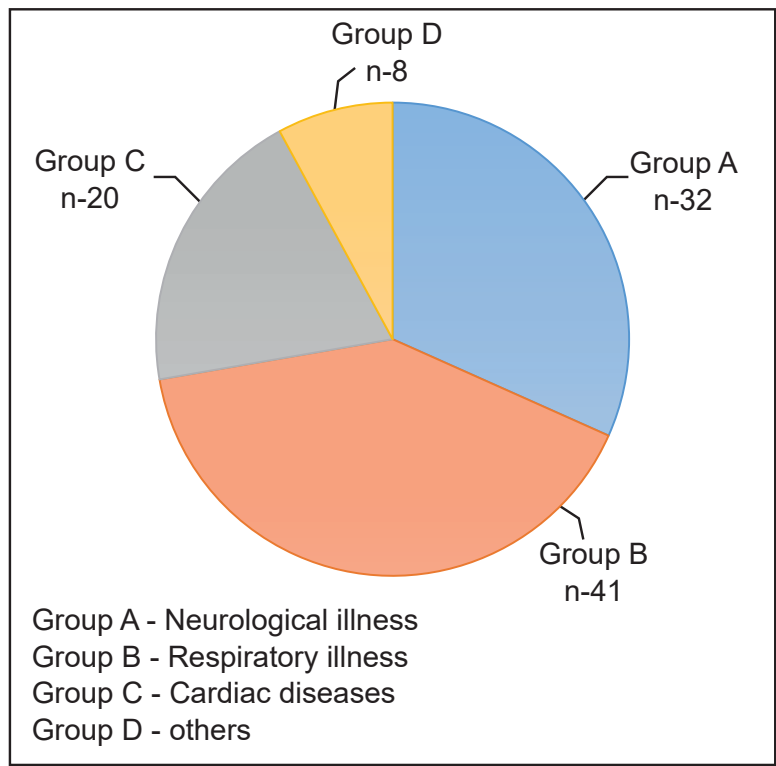

Fig. 1: Distribution of the study groups. 
Table 1: Demographics and clinical characteristics of patients who received mechanical ventilation

\begin{tabular}{|c|c|}
\hline Characteristic & $\begin{array}{c}\text { Mechanically } \\
\text { Ventilated Patients: } \\
\text { Number (\%) }\end{array}$ \\
\hline Total & 101 \\
\hline$<1$ year & $42(41.6)$ \\
\hline$\geq 1$ years & $59(58.4)$ \\
\hline Female & $25(24.7)$ \\
\hline Male & $76(75.2)$ \\
\hline \multicolumn{2}{|l|}{ Aetiology of MV } \\
\hline Neurological & $30(29.7)$ \\
\hline Pneumonia & $28(27.7)$ \\
\hline Sepsis & $28(27.7)$ \\
\hline Cardiovascular & $11(10.9)$ \\
\hline Co morbidities & $68(67.3)$ \\
\hline \multicolumn{2}{|l|}{ Outcome } \\
\hline Extubated & $48(47.5)$ \\
\hline Death & $39(38.6)$ \\
\hline LAMA & $11(10.9)$ \\
\hline Tracheostomy & $3(2.9)$ \\
\hline \multicolumn{2}{|l|}{ Complications } \\
\hline $\begin{array}{l}\text { Ventilator associated } \\
\text { pneumonia }\end{array}$ & $6(5.9)$ \\
\hline Upper lobe atelectasis & $1(0.9)$ \\
\hline Pneumothorax & $3(2.9)$ \\
\hline Spontaneously extubated & $1(0.9)$ \\
\hline
\end{tabular}

Note: LAMA - left against medical advice.

Table 2: Indications of Mechanical Ventilation

\begin{tabular}{lc}
\hline Indications & Number (\%) \\
\hline Respiratory failure & $35(34.6)$ \\
\hline Low GCS & $18(17.8)$ \\
\hline Shock & $14(13.8)$ \\
\hline Status Epilepticus & $11(10.9)$ \\
\hline ARDS/ALI & $7(6.9)$ \\
\hline Imminent Arrest & $5(4.9)$ \\
\hline Pulmonary Edema & $5(4.9)$ \\
\hline Increased ICP & $4(3.9)$ \\
\hline
\end{tabular}

Note: GCS- Glasgow coma scale, ARDS- acute respiratory distress syndrome, ALI- acute lung injury, ICP- increased intracranial pressure
Table 3 describes the duration of mechanical ventilation and inotropes among various study groups along with the length of stay in the ICU. The median of mechanically ventilated days was 6.6 days in group A and B. Group B had a longer duration of ventilation as compared to other groups. The mortality rate among the critically ill mechanically ventilated patients in our cohort was of $38.6 \%$, with group B having the highest mortality rate. The mortality rates increased as the number of failing organs increased. The mean duration of hospital stay was 15.7, 15, 8.6 and 11.4 days for group A, B, C and $D$ respectively.

\section{Discussion}

During the study period of three years 101 patients' required invasive mechanical ventilation and 34 required non-invasive mechanical ventilation. Shirly GFA $^{7}$ reported 111 patients were ventilated in their study as compared to 102 and 56 ventilated patients in studies done by Chitale $\mathrm{SV}^{8}$. and Dharmaraj ${ }^{9}$. during a period of one year. The incidence of MV including noninvasive ventilation in our study was $11.5 \%$ which is less than a study done at Telangana by Ayesha (23\%). The percentage of paediatric patients mechanically ventilated in different PICUs varies from $14-60 \% \%^{1,2,10,11}$. Vigayakumary ${ }^{6}$ reported that $52 \%$ of children received MV in PICU of Sri Lanka whereas Khemani and Wolfler showed the frequency of MV in their study to be $30 \%$ and $34.6 \%$ respectively. Shirly GFA published that $21.6 \%$ of children in a government tertiary care hospital in India were mechanically ventilated annually. The reason behind the low rate of MV in our study could be due to early initiation of non-invasive ventilation and absence of cardiac intensive care unit. The most common reason for initiation of $\mathrm{MV}$ was impending respiratory failure (34.6\%) with an underlying aetiology of bronchopneumonia in this study. Studies made by Kendril Dafne Cardoso in Brazil and Shirly GFA in India also observed respiratory failure was the commonest cause of initiation of MV. However, Wolfler and Dharmaraj. found neurological illness was the most common reason for MV in their PICUs. The most likely explanation for this disparities could be that, the aetiology of PICU admissions varies in different countries and it depends on the disease prevalent in that region.

Table 3: Duration of Mechanical Ventilation, Length of Stay and mortality rate in the Intensive Care Unit

\begin{tabular}{lccccc}
\hline Parameters & $\begin{array}{c}\text { Group A } \\
\mathbf{N}=\mathbf{3 2}\end{array}$ & $\begin{array}{c}\text { Group B } \\
\mathbf{N}=\mathbf{4 1}\end{array}$ & $\begin{array}{c}\text { Group C } \\
\mathbf{N}=\mathbf{2 0}\end{array}$ & $\begin{array}{c}\text { Group D } \\
\mathbf{N}=\mathbf{8}\end{array}$ & $p$-value \\
\hline Duration of MV in days; median (range) & $4(1-40)$ & $6(1-21)$ & $1.5(1-13)$ & $2(1-6)$ & $0.001^{\star \$}$ \\
\hline Duration of inotropes in days; median (range) & $3(1-10)$ & $4(1-10)$ & $1(1-10)$ & $5.5(2-6)$ & 0.177 \\
\hline LOS in ICU; median (range) & $11(1-60)$ & $12(1-75)$ & $6(1-35)$ & $12.5(2-19)$ & 0.128 \\
\hline Mortality Rate; $n(\%)$ & $11(28.2)$ & $13(33.3)$ & $13(33.3)$ & $2(5.1)$ & 0.064 \\
\hline
\end{tabular}

*Significant between group B and group C, ${ }^{\$}$ Significant between group B and group D 
Complications are common among mechanically ventilated children in $\mathrm{PICU}^{12}$. The complication rate in our cohort was $10.8 \%$ as compared to $9.2 \%$ reported by Mukhtar ${ }^{13}$. Ventilator associated pneumonia was identified as the commonest complication in our study followed by upper lobe atelectasis. VAP was observed in $32 \%, 27.4 \%, 17.5 \%$ and $10.7 \%$ by Srinivasan, Tullu, Kendirli and Casado respectively ${ }^{14,15,16,17}$. The incidence of ventilator associated pneumonia in the present study was $5.9 \%$ which is much lower as compared to the above-mentioned studies. In this study the highest recorded complication occurred in group $A$.

The duration of mechanical ventilation was 4-6 days in few published reports ${ }^{1,2}$. The median duration of mechanical ventilation in our PICU was four days. $11.8 \%$ required ventilatory support for more than 10 days. Length of stay in PICU was highest in group B. Co morbidity was present in $67.3 \%$ of the study population. The major co morbid condition in our study was congenital heart disease which is similar to that observed by Payen $\mathrm{V}^{18}$. Volakli observed a co morbidity of $41.3 \%$ in their study ${ }^{19}$. The mortality rate among the mechanically ventilated patients in our study was $38.6 \%$ which is comparable to that observed by Shirly GFA et al (36.9\%). A mortality rate of as high as $58.3 \%$ was observed by Kendirli in contrast to as low as $4.5 \%$ observed by $\operatorname{Tan}^{20}$. Vijayakumary reported $27.6 \%$ mortality rate in his study done in Sri Lanka. In developed countries, the overall mortality rates in mechanically ventilated patients in PICUs was less than $2 \%{ }^{2}$.The mortality rate was high in group $B(33.3 \%)$ and C (33.3\%) followed by group A $(28.2 \%)$ but was statistically insignificant $(p=0.064)$. The limitation of this study was lack of severity of scoring of these patients which could have led to a biased favourable outcome in the form of low mortality rate.

\section{Conclusion}

Respiratory failure was the most common cause of MV, frequency of MV was low probably because of less critically ill children being admitted due to absence of super-specialities. Ventilator associated pneumonia was the most common complication in these patients. A favourable outcome in form of low mortality rate in our study is noteworthy.

7. Shirly GFA, Lakshmi S, Shanthi S, et al. Clinical profile of children mechanically ventilated in a pediatric intensive care unit of a limited resource setting. Int J Contemp Pediatr 2016;3(2):542-545. DOI: 10.18203/2349-3291. ijcp20182530

8. Citale SV, Behera MK. Study and outcome of mechanically-ventilated paediatric patients in intensive care setup in tertiary care hospital. J Evid Based Med Health 2017;4(37); 2218-22. DOI: https://doi. org/10.18410/jebmh/2017/435

9. Dharmaraj S, Panneerselvam R. Morbidity pattern and outcome of mechanically ventilated children in a paediatric intensive care unit of a rural medical college. Int J Sci Study 2016;4(2):27-29. DOI: 10.17354/ ijss/2016/245

10. Farias JA, Fernandez A, Monteverde E, Flores JC,Baltodano A, Menchaca A. Mechanical ventilation in pediatric intensive care units during the season for acute lower respiratory infection: a multicenter study. Pediatr Crit Care Med 2012;13(2):158-64. DOI: 10.1097/PCC.0b013e3182257b82.

11. Khemani RG, Markovitz BP, Curley MA. Characteristics of children intubated and mechanically ventilated in 16 PICUs. Chest 2009;136(3):765-71. DOI: 10.1378/ chest.09-0207

12. Principi T, Fraser DD, Morrison GC, Farsi SA, Carrelas JF, Maurice EA, et al. Complications of mechanical ventilation in the pediatric population. Pediatr Pulmonol 2011;46(5):452-57. DOI: 10.1002/ppul.21389. 
13. Mukhtar B, Siddiqui N R, Haque A. Clinical Characteristics and Immediate-Outcome of Children Mechanically Ventilated in PICU of Pakistan. Pak J Med Sci 2014;30(5):927-30. DOI:10.12669/pjms.305.5159

14. Kendirli T, Kavaz A, Yalaki Z, Ozturk-Hismi B, Derelli $E$, İnce $E$. Mechanical ventilation in children. Turk $J$ Pediatr 2006;48(4):323.

15. Srinivasan R, Asselin J, Gildengorin G, Wiener-Kronish J, Flori HR. A prospective study of ventilator-associated pneumonia in children. Pediatrics 2009;123(4):110815. DOI: 10.1542/peds.2008-1211.

16. Casado RJA, de Mello MJG, de Aragão RCF, de Albuquerque $\mathrm{M}$ de FPM, Correia JB. Incidence and risk factors for health care-associated pneumonia in a pediatric intensive care unit. Crit Care Med 2011;39(8):1968-73. DOI: 10.1097/ CCM.0b013e31821b840d
17. Tullu MS, Deshmukh CT, Baveja SM. Bacterial nosocomial pneumonia in Paediatric Intensive Care Unit. J Postgrad Med 2000;46(1):18-22.

18. Payen V, Jouvet P, Lacroix J, Ducruet T, Gauvin F. Risk factors associated with increased length of mechanical ventilation in children. Pediatr Crit Care Med 2012;13(2):152- 7 . DOI: 10.1097/ PCC.0b013e3182257a24.

19. Volakli E, Sdougka M, Tamiolaki M, Tsonidis C, Reizoglou M, Giala M. Demographic profile and outcome analysis of pediatric intensive care patients. Hippokratia 2011;15(4):316-22.

20. Tan GH, Tan TH, Goh DYT, Yap HK. Risk factors for predicting mortality in a paediatric intensive care unit. Ann-Acad Med Singa 1998; 27:813-18. 